\title{
Reducing inappropriate antibiotic prescribing in the residential care setting: current perspectives
}

This article was published in the following Dove Press journal:

Clinical Interventions in Aging

13 January 2014

Number of times this article has been viewed

\author{
Ching Jou Lim' \\ David CM Kong' \\ Rhonda L Stuart ${ }^{2,3}$ \\ 'Centre for Medicine Use and \\ Safety, Monash University, Parkville, \\ VIC, Australia; ${ }^{2}$ Monash Infectious \\ Diseases, Monash Health, Clayton, \\ VIC, Australia; ${ }^{3}$ Department of \\ Medicine, Monash University, Clayton, \\ VIC, Australia
}

\begin{abstract}
Residential aged care facilities are increasingly identified as having a high burden of infection, resulting in subsequent antibiotic use, compounded by the complexity of patient demographics and medical care. Of particular concern is the recent emergence of multidrugresistant organisms among this vulnerable population. Accordingly, antimicrobial stewardship (AMS) programs have started to be introduced into the residential aged care facilities setting to promote judicious antimicrobial use. However, to successfully implement AMS programs, there are unique challenges pertaining to this resource-limited setting that need to be addressed. In this review, we summarize the epidemiology of infections in this population and review studies that explore antibiotic use and prescribing patterns. Specific attention is paid to issues relating to inappropriate or suboptimal antibiotic prescribing to guide future AMS interventions.

Keywords: residential aged care, health care-associated infection, surveillance, multidrugresistant, antibiotic prescribing, antimicrobial stewardship
\end{abstract}

\section{Introduction}

Long-term care facilities (LTCF) refer to an array of residential and outpatient facilities designed to meet the biopsychosocial needs of persons with sustained selfcare deficits. ${ }^{1,2}$ These include residential aged care facilities (RACFs), nursing homes, skilled nursing facilities, assisted living facilities, retirement homes, and so on. In the literature, these terms may vary across different geographical areas; for instance, LTCF is a term more frequently used in the United States, whereas the term RACF is more commonly applied in other countries like Australia. In general, there is considerable overlap between an LTCF and an RACF; all of these terms refer to a health care setting that provides long-term nursing care to the elderly in the community. ${ }^{2}$ This article is mainly focused on studies described in the context of RACFs and/or nursing homes, with less emphasis placed on other LTCF settings, unless otherwise specified. The term RACF, instead of LTCF, will be used throughout this article.

The elderly population in RACF represents a wide spectrum of clinical disability. The majority of these individuals are vulnerable to infections due to frailty, poor functional status, multiple comorbidities, and compromised immune systems..$^{3-5}$ Bed-bound residents are generally at greater risk of skin infections, ${ }^{6}$ while those with urine and fecal incontinence have an increased risk of urinary tract infections. ${ }^{5}$ In addition, close living proximity and frequent nurse-resident contact facilitate the spread of organisms among RACF residents. ${ }^{3}$ This condition, coupled with the to and fro nature between RACF and acute hospital setting, promotes a higher infection burden among residents in RACF compared to community dwellers. ${ }^{7,8}$
Correspondence: Rhonda L Stuart Monash Infectious Diseases, Monash Health, Level 3, 246 Clayton Road, Clayton, VIC, 3168, Australia Tel +6I 395944564

Fax +6I 395944533

Email rhonda.stuart@monashhealth.org 
Although the infection burden among the RACF population has long been recognized, infection prevention efforts are often limited to infection surveillance activity. Of concern is the widespread antibiotic prescribing in RACFs, which may lead to the emergence of antibiotic resistance. Studies have reported an increasing use of broad-spectrum oral antibiotics, such as quinolones, among this population, with up to $75 \%$ of use judged to be inappropriate. ${ }^{9,10}$ In an era where multidrug-resistant (MDR) organisms are emerging in the community, RACF residents have been increasingly identified as important reservoirs for this development. ${ }^{11,12}$ This trend highlights an immediate need to promote judicious antibiotic use in this population. However, unlike the acute care hospital setting, there are major practical challenges for implementing more targeted infection control and antimicrobial stewardship (AMS) strategies within this resourcelimited environment. ${ }^{13}$

This review focuses on issues about inappropriate antibiotic use and the unique role of AMS in the RACF setting, with particular focus on comparisons between the US and Australasian settings. Additionally, it will also cover the epidemiology of health care-associated infections, trends of various MDR organisms, experiences of AMS interventions in the RACF setting, and future directions or recommendations for efforts to optimize antibiotic use.

\section{Surveillance of health care- associated infections in RACFs}

An effective infection surveillance system serves as a useful tool to help reduce health care-associated infections. ${ }^{14}$ Health care-associated infection rates in RACFs have been widely reported using either single-day point prevalence surveys or long-term surveillance studies, with prevalence rates between $2.8 \%-16.2 \%,{ }^{6,15-24}$ and incidence rates ranging from 1.8-9.5 infections per 1,000 resident-care days reported worldwide. ${ }^{25-34}$ However, a direct comparison of infection rates across wide geographical areas is not practical, partly due to differences in infection surveillance methodologies.

A European, multinational approach to infection surveillance, known as "Healthcare-Associated Infection in European Long-Term Care Facilities" (HALT) was introduced in $2008 .{ }^{13}$ This surveillance activity aimed to provide a tool for the assessment of infection burden, which was used to guide European RACFs infection prevention and control programs. Similarly, in the US, a mandatory requirement for all RACFs to maintain regular documentation of recent infections allows for the ongoing surveillance of infection data: ${ }^{35}$ such large-scale surveillance activity remains scant in other countries.

An effective infection surveillance system requires valid uniform definitions for various infectious syndromes to allow for interfacility comparisons. Residential care-specific surveillance criteria for defining infections, known as the McGeer criteria, were originally developed by a Canadian consensus group in $1991 .{ }^{36}$ Although several criticisms were raised to challenge the validity of these definitions, ${ }^{37,38}$ the McGeer criteria remained the most widely used infection definitions for surveillance purposes in the RACF setting worldwide. ${ }^{39}$ Recently, the McGeer criteria were revised in an effort to establish more evidence-based criteria, with a focus on preventable infections ${ }^{40}$ However, the feasibility of the revised criteria, which require laboratory confirmation for the diagnosis of respiratory and urinary tract infections, warrants further research.

Despite the wide variation of the incidence or prevalence rates reported in the literature, the three most frequently reported infections in RACFs are urinary tract infections (UTIs), respiratory tract infections (RTIs), and skin and soft tissue infections. ${ }^{6,16,18,24,28,29,34}$ Several studies have reported that UTIs and RTIs were also the most commonly observed causes for hospital admissions among the elderly from RACFs. ${ }^{7,41,42}$ Common occurrences of infectious syndromes in the absence of on-site diagnostic facilities or timely expert support have been reported to result in the frequent transfer of RACF residents to acute care hospitals. ${ }^{43}$ Besides incurring higher health care costs, frequent resident referrals to hospitals were shown to be associated with poorer clinical outcomes. ${ }^{44,45}$ Consequently, there has been a preference in promoting the management of infections within RACFs to avert hospital admissions. This, however, raises other practical issues, particularly the availability of infectious disease expertise and support to provide reasonable standards of infection management in the RACFs.

\section{Epidemiology of multidrug-resistant organisms in the RACF setting}

The RACF population has been increasingly recognized as an important reservoir for the transmission of MDR organisms in the community. ${ }^{46,47}$ Several studies have reported that this population is at high risk for carrying MDR organisms, with such patients warranting broad-spectrum empiric antibiotic therapy upon hospital admission. ${ }^{11,12}$

Traditionally, methicillin-resistant Staphylococcus aureus (MRSA) and vancomycin-resistant Enterococci (VRE) were recognized as common culprits causing various health 
care-associated infections in the RACF setting. ${ }^{1}$ Thus, infection control strategies have focused largely on preventing the transmission of these organisms among RACF residents. . $^{1,48}$ However, in recent years, there has been an emerging trend of MDR gram-negative Bacilli (GNB) seen among this population. Based on studies exploring the carriage of three major groups of MDR organisms (ie, MRSA, VRE, and MDR GNB), there appears to be a shift in the epidemiology of MDR organisms in the RACF over the last decades. ${ }^{49}$ Indeed, studies conducted in the 1990s and early 2000s have demonstrated that MDR GNB colonization was less commonly found in comparison to MRSA and VRE. ${ }^{50-52}$ On the contrary, studies conducted in the late 2000s have shown an emergence of MDR GNB, with some studies reporting colonization rates far exceeding that of MRSA and VRE. ${ }^{47,53,54}$ The emergence of MDR GNB is not limited to the asymptomatic carriage of these organisms. O'Fallon et $\mathrm{al}^{46}$ examined 1,661 clinical cultures to compare the presence of MRSA, VRE, and MDR GNB over a 2-year period. The authors noted that MDR GNB (11\%) were isolated more frequently than MRSA $(6 \%)$ or VRE (1\%), and that there appeared to be a steady rise in MDR GNB isolates. ${ }^{46}$

In view of existing infection control guidelines mainly addressing MDR gram-positive organisms (ie, MRSA and VRE), a shift of attention in infection control strategies that focus on the emergence of MDR GNB among RACF residents is warranted. Furthermore, the increasing trend of MDR GNB infections poses significant challenges to the existing option for antibiotic therapy, given the limited number of MDR GNB active antibiotics currently available or in development. ${ }^{55}$ Fundamentally, awareness about this shift in trends is important, first as it informs the potential change of empiric antibiotic treatment among this high-risk population, and second, it encourages that microbiological investigations guide appropriate antibiotic use.

Prior exposure to antibiotics appears as one of the most prominent risk factors associated with colonization and infection of both MDR gram-positive and gram-negative organisms. ${ }^{53,54,56-60}$ Specific antibiotics most frequently associated with MDR organisms include fluoroquinolones ${ }^{60-66}$ and trimethoprim-sulfamethoxazole. ${ }^{60,67}$ Indeed, several studies have highlighted that inappropriate and excessive use of antimicrobials has led to the development of antimicrobial resistance in the long-term care setting. ${ }^{60,61,68-71}$ In comparison to other age-related risk factors, such as the presence of wound or pressure ulcers and reduced functionality (which are not modifiable to any great extent), reducing unnecessary or widespread use of antibiotics might be a more straightforward and critical strategy to curb the rapid emergence of MDR organisms.

\section{Global snapshot of antibiotic use in RACFs}

Inevitably, rising infection burden predisposes an individual to increased antibiotic prescription, and this high burden of antibiotic use in RACFs has been evident in numerous studies. ${ }^{72-77}$ It has been reported that exposure to at least one course of antimicrobials occurs in $50 \%-80 \%$ of RACF residents annually. ${ }^{72-77}$ In the US, antimicrobial agents have been shown to be among the most frequently prescribed medications in RACFs, accounting for almost $40 \%$ of all the systemic drugs prescribed, ${ }^{78}$ with more than one in ten residents receiving an antimicrobial at any given time. ${ }^{9}$ There is a wide variation in the reported antimicrobial use patterns in RACFs, as summarized in Table 1.

A cross-national surveillance on antimicrobial prescribing in nursing homes across 15 European countries demonstrated dramatic differences in antibiotic use (in defined daily doses/1,000 residents/day), ranging from 5.9 in Germany to 135.7 in northern Ireland in the first survey, and from 15.3 in Latvia to 121.9 in Italy in the second survey 7 months later. ${ }^{83}$ The reasons for the observed variations in antibiotic use patterns are multifactorial, and include factors associated with the resident (resident and clinical characteristics, infection burden) and the facility (size of the RACFs, institutional antibiotic policy). Interestingly, a population-based study involving 363 RACFs in Canada showed that variations in antibiotic prescribing did not appear to be driven by residentor facility-associated factors; instead, it was influenced by the prescriber's preference. ${ }^{72,81}$ These findings suggest that interventions to improve antibiotic use should include influencing the antibiotic prescribing behavior of the prescribers.

The most commonly prescribed antibiotics in RACFs (Table 1) vary across different countries, with patterns more comparable in studies conducted within the same country. ${ }^{24,34,85}$ The prescribing patterns are influenced by national and regional antibiotic guidelines. For instance, the US and Canadian RACFs commonly report significant use of quinolones, ${ }^{9,72}$ while other countries such as Australia show lower use of these antimicrobials. ${ }^{34}$ Likewise, the use of intravenous (IV) antibiotics is influenced by the policy or health care model of the individual RACFs. Some facilities report that $7 \%-9 \%$ of antimicrobials are given parenterally, ${ }^{60,88}$ while others claim a $<1 \%$ usage of IV therapy. ${ }^{20,86}$ In a cross-sectional study involving 21 European countries, the proportions of parenteral antibiotics differed considerably 
Table I Studies describing antibiotic prescribing patterns in RACF across different countries

\begin{tabular}{|c|c|c|}
\hline $\begin{array}{l}\text { Authors (country, year of } \\
\text { surveillance, study size) }\end{array}$ & $\begin{array}{l}\text { Rates of antibiotic use; most common } \\
\text { antibiotics }\end{array}$ & Issues of concern highlighted in the study \\
\hline \multicolumn{3}{|c|}{ Point prevalence survey - prevalence: (residents receiving $\geq I$ antibiotic)/(all residents) } \\
\hline $\begin{array}{l}\text { Zimmer et al } 7^{79} \\
\text { (US, 1983, } 42 \text { RACFs) }\end{array}$ & $\begin{array}{l}\text { Prevalence: } 173 / 2,238(8 \%) \text {; trimethoprim/sulfamethoxazole } \\
\text { (43\%) ampicillin or amoxicillin (19\%), } \\
\text { nitrofurantoin (8\%) }\end{array}$ & $\begin{array}{l}\text { Evidence to initiate the antibiotic was judged as } \\
\text { adequate in } 62 \% \text { of cases based on an expert panel. } \\
\text { Main concern is high proportion of empiric antibiotic } \\
\text { therapy without prior investigation. }\end{array}$ \\
\hline $\begin{array}{l}\text { Pakyz and Dwyer } 9 \\
\text { (US, 2004, I I } 74 \text { RACFs) }\end{array}$ & $\begin{array}{l}\text { Prevalence: } 161,599 / 1,330,608(11 \%) \\
\text { nitrofurantoin }(12 \%) \text {, levofloxacin }(12 \%) \text {, } \\
\text { and ciprofloxacin }(7 \%)\end{array}$ & No assessment on the appropriateness of antibiotic use. \\
\hline $\begin{array}{l}\text { Moro et } \mathrm{al}^{22} \\
\text { (Italy, 2007, } 49 \text { RACFs) }\end{array}$ & $\begin{array}{l}\text { Prevalence: } 234 / 1,926 \text { (12\%); most common } \\
\text { antibiotics not specified }\end{array}$ & $\begin{array}{l}27 \text { of } 122 \text { patients ( } 22 \%) \text { receiving systemic antimicrobials } \\
\text { with reason for antibiotic therapy not clear. }\end{array}$ \\
\hline $\begin{array}{l}\text { Latour et } \mathrm{l}^{80} \\
\text { (2I European countries, } \\
2009,323 \text { RACFs) }\end{array}$ & $\begin{array}{l}\text { Prevalence: I,966/32,685 (6\%); } \\
\beta \text {-lactam penicillins ( } 29 \%) \text {, quinolones ( } 14 \%) \text {, } \\
\text { other beta-lactam antibiotics (I I\%) }\end{array}$ & $\begin{array}{l}\text { Empirical treatments were most common ( } 54 \% \text { of all } \\
\text { antibiotic use), followed by prophylactic }(29 \%) \text { and } \\
\text { microbiologically documented treatments }(16 \%) \text {. }\end{array}$ \\
\hline $\begin{array}{l}\text { Daneman et al } \\
\text { (Canada, 2009, } 363 \text { RACFs) }\end{array}$ & $\begin{array}{l}\text { Prevalence: } 2,190 / 37,37 \mid(6 \%) \text {; } \\
\text { nitrofurantoin (15\%), trimethoprim/sulfamethoxazole } \\
\text { (14\%), and ciprofloxacin (13\%) }\end{array}$ & $\begin{array}{l}\text { Treatment courses were at least } 10 \text { days in duration } \\
(63 \%) \text {, and many exceeded } 90 \text { days ( } 21 \%) \text {, suggesting } \\
\text { chronic prophylaxis. }\end{array}$ \\
\hline $\begin{array}{l}\text { Rummukainen et al }{ }^{82} \\
\text { (Finland, 2009, nine RACFs) }\end{array}$ & $\begin{array}{l}\text { Prevalence: } 716 / 5,691 \text { (13\%); methenamine (4I\%), } \\
\text { trimethoprim (14\%), and pivmecillinam (II\%) }\end{array}$ & $\begin{array}{l}\text { The prophylaxis of UTIs was the most common } \\
\text { indication for antibiotic use. }\end{array}$ \\
\hline McClean et $a^{83}$ & Prevalence of two surveys: $6.5 \%$ in April/5. $0 \%$ in November; & No assessment on the appropriateness of antibiotic use. \\
\hline
\end{tabular}

(I5 European countries, 2009, 85 RACFs)

Cotter et al ${ }^{16}$ (Ireland, 2010, 69 RACFs) methenamine (I8\%), trimethoprim (II\%), and co-amoxiclav (I I\%) in April and co-amoxiclav (12\%), nitrofurantoin (12\%) and methenamine (12\%) in November Prevalence: 426/4, 170 (10\%); most common antibiotics not specified

Moro et al ${ }^{23}$ (Italy, 2010, 92 RACFs)

McClean et al ${ }^{84}$ (Ireland, 2010-201I, 30 RACFs)

Stuart et a $\left.\right|^{85}$ (Australia, 20I I, five RACFs)

Smith et $\mathrm{al}^{24}$

(Australia, 20II, 29 RACFs)

Heudorf et al ${ }^{20}$

(German, 20I I, 40 RACFs)

Prevalence: 438/9,285 (5\%); quinolones (24\%), penicillin plus beta-lactamase inhibitor (22\%), and third-generation cephalosporins (21\%) Prevalence: $9 \%$ systemic antibiotic, $6 \%$ topical antibiotic; trimethoprim, cephalexin, and nitrofurantoin were most commonly prescribed Prevalence: 23/257 (9\%); doxycycline (26\%), cephalexin (17\%) and flucloxacillin (13\%), or trimethoprim (13\%)

Prevalence: 63/757 (8\%); cephalexin (33\%), amoxicillin, trimethoprim, and nitrofurantoin (10\% each)

Prevalence: 90/3,732 (2\%); quinolones $(n=31)$, cephalosporins $(n=19)$, penicillins $(n=\mid 1)$, and co-trimethoprim/sulfamethoxazole $(n=I I)$

Longitudinal surveillance Mylotte $^{75}$ (US, 1989, single RACF) I I I/I56 (7I\%) received $\geq$ I incident course a year Incidence: $0.6 \mathrm{I}$ antibiotic course/ 100 patient-days; trimethoprim/sulfamethoxazole (29\%), ciprofloxacin (26\%), amoxycillin ( $12 \%)$

Warren et $\mathrm{a}^{17}$ (US, 1991, 53 RACFs) 2, 105/3,899 (54\%) received $\geq I$ incident course a year Incidence: 0.46 antibiotic course/ 100 patient-days; beta-lactam antibiotics (54\%) most common

Loeb et a ${ }^{74}$ (Canada, 1996, 22 RACFs)

2,408/3,656 (66\%) received $\geq I$ incident course a year Incidence: 0.73 antibiotic course/ 100 patient-days; trimethoprim-sulphamethoxazole, (I7\%) ciprofloxacin (17\%), amoxicillin (13\%)

Blix et al ${ }^{86}$ (Norway, 2003, I 33 RACFs)
Incidence: range 4-44 DDD/I00 patient-days; penicillins with extended spectrum, followed by trimethoprim and sulfonamides
Up to $40 \%$ of total prescriptions were for prophylactic indications.

Only $57 \%$ of residents prescribed antibiotics for UTI had a microbiological investigation.

Only 49\% treatment given for McGeer modified confirmed infection, $30 \%$ nonconfirmed infection, and $21 \%$ no documented infection.

High use of topical antimicrobial for prolonged duration. Based on antibiotic guidelines, almost $25 \%$ of systemic antibiotics were prescribed at inappropriate doses. A total $26 \%$ of antibiotic use was given for prophylactic reasons. Up to $40 \%$ did not fulfill the McGeer criteria for bacterial infection.

Up to $39 \%$ of total prescriptions were for prophylactic indications.

Empiric prescribing without microbiological investigation for UTIs ( $92 \%$ of antibiotic treatment)

\section{ent-days)}

Questionable high use of fluoroquinolones as empiric therapy.

\footnotetext{
$>50 \%$ of antibiotic courses started without documented investigation. Treatments were initiated for "viral" upper respiratory infections (13\%) and asymptomatic bacteriuria (9\%)

McGeer criteria were only met in $49 \%$ of patients prescribed antibiotics; $30 \%$ of antibiotic prescriptions for urinary indication were for asymptomatic bacteriuria.

High use of a urinary prophylactic agent, methenamine, represented nearly half (46\%) of DDDs used.
} 
Table I (Continued)

\begin{tabular}{|c|c|c|}
\hline $\begin{array}{l}\text { Authors (country, year, } \\
\text { study size) }\end{array}$ & $\begin{array}{l}\text { Rates of antibiotic use; } \\
\text { most common antibiotics }\end{array}$ & $\begin{array}{l}\text { Issues of concern highlighted } \\
\text { in the study }\end{array}$ \\
\hline $\begin{array}{l}\text { Pettersson et } \mathrm{al}^{87} \\
\text { (Sweden, 2003, } 58 \text { RACFs) }\end{array}$ & $\begin{array}{l}\text { Incidence: one treatment/resident/year; } \\
\text { penicillins (38\%), followed by quinolones (23\%) } \\
\text { and trimethoprim (18\%) }\end{array}$ & $\begin{array}{l}\text { Based on national guidelines, } 50 \% \text { of lower UTIs } \\
\text { in women were not treated according to the } \\
\text { recommendations (questionable length of treatment and } \\
\text { overprescribing of quinolones). }\end{array}$ \\
\hline $\begin{array}{l}\text { Lim et } \mathrm{al}^{34} \\
\text { (Australia, 2010, four RACFs) }\end{array}$ & $\begin{array}{l}\text { Incidence: } 0.7 \text { I antibiotic course/ } 100 \text { patient-days; } \\
\text { cephalexin ( } 25 \%) \text {, trimethoprim (I } 4 \%) \text {, } \\
\text { amoxycillin-clavulanate (I3\%) }\end{array}$ & $\begin{array}{l}\text { Up to } 37 \% \text { did not fulfill the McGeer criteria for } \\
\text { bacterial infection. Antimicrobials were routinely } \\
\text { prescribed for URTI and acute bronchitis (31\%), } \\
\text { also common for asymptomatic bacteriuria. }\end{array}$ \\
\hline $\begin{array}{l}\text { Daneman et } \mathrm{al}^{72} \\
\text { (Canada, 2010, } 630 \text { RACFs) }\end{array}$ & $\begin{array}{l}50,061 / 66,901(75 \%) \text { received } \geq 1 \text { incident course } \\
\text { a year; second-generation fluoroquinolones }(19 \%), \\
\text { penicillins }(17 \%) \text {, third-generation fluoroquinolones }(17 \%)\end{array}$ & $\begin{array}{l}\text { Prolonged treatment courses were common for } \\
\text { all antibiotic subclasses, with } 45 \% \text { that exceeded } \\
\text { a 7-day course. }\end{array}$ \\
\hline
\end{tabular}

Abbreviations: RACFs, residential aged care facilities; UTI, urinary tract infection; n, number; DDD, defined daily dose; URTI, upper respiratory tract infection.

between and within countries (range: $0 \%-67 \%) .{ }^{88}$ Parenteral antibiotics were most commonly prescribed for pneumonia, with one study reporting that more than half of the prescribed antibiotics for suspected pneumonia were administered parenterally. ${ }^{89}$

\section{Assessing the appropriateness of antibiotic use}

Studies examining antibiotic prescribing practices vary in a number of ways, particularly with regard to the standard that is used for judging the antibiotic's appropriateness. To date, the evidence on which to base definitive recommendations for antibiotic use in the RACF setting is lacking. There are several published clinical practice guidelines available to assist the diagnostic evaluation process ${ }^{90,91}$ and empiric antibiotic prescribing decisions ${ }^{78,92}$ in the RACF setting. These guidelines account for the barriers and difficulties specific to this resource-limited setting, but they are tailored for the US long-term care setting. For instance, Nicolle et al ${ }^{78}$ have recommended quinolones and IV aminoglycoside as first-line empirical antibiotic treatments for UTIs. The applicability of these guidelines outside the US system remains unknown, and reports on adherence to these guidelines are rare. A recent study involving 12 RACFs in North Carolina has shown that only $13 \%$ of antibiotic prescriptions were classified as adherent to the Loeb minimum criteria, a consensus standard for the initiation of empiric antibiotics among residents of RACFs. ${ }^{92,93}$

Previous studies have applied various approaches or definitions to assess the "appropriateness" of antibiotics prescribed in RACFs. These include the use of an "expert panel", 79,94 validation according to the McGeer criteria, ${ }^{22,34,74,85}$ and concordance with published antibiotic guidelines.$^{84,87,95}$ Regardless of the differences in criteria used for judging appropriateness,
$40 \%-75 \%$ of antibiotic use has been claimed to be inappropriate. ${ }^{10,22,74,79,85,87,94}$ The McGeer criteria were developed for the purpose of establishing surveillance definitions rather than to assist in clinical decision making. Thus, they should be considered as conservative guidelines for assessing antibiotic use, and the data pertaining to "inappropriate" antibiotic use based on these criteria should be interpreted with caution.

\section{Areas of potential antibiotic misuse}

To assist the development of evidence-based antibiotic prescribing practices applicable in the RACF setting, it is essential to identify areas of potential antibiotic misuse specific to this setting. Major issues of potential antibiotic misuse among this population that warrant further investigations and improvements have been highlighted in Table 1 . These issues are highlighted as follows:

1. Prophylactic antibiotic for UTI. ${ }^{16,24,82,86}$ Evidence on the effectiveness of this strategy among institutionalized elderly patients in RACF remains scant. Prolonged antibiotic use in the absence of infection inevitably selects for resistant organisms. A study by Blix et $\mathrm{al}^{86}$ showed that methenamine, a urinary prophylactic agent, represented nearly half of the defined daily doses used. The high use of this agent is problematic, with inconclusive evidence to support its use for long-term urinary prophylaxis in the latest Cochrane Review. ${ }^{96}$

2. Empiric prescribing without microbiological investigation. ${ }^{20,77,79,80}$ Studies have reported that only about $15 \%$ of antibiotic treatment was given empirically without microbiological investigation. ${ }^{20,80}$ Inappropriate antibiotic use is associated with worse clinical outcomes and, in some cases, increased mortality. ${ }^{97}$ Therefore, causative etiologic agents should be identified, especially in symptomatic UTIs, to guide the adjustment of empiric antibiotic therapy. 
3. Treatment of asymptomatic bacteriuria. ${ }^{34,74,77}$ There is compelling evidence from several randomized controlled trials that strongly support not treating asymptomatic bacteriuria in institutionalized elderly patients, given the lack of treatment benefit, ${ }^{98-100}$ and the patients' association with the emergence of antibiotic resistance. ${ }^{101}$ Asymptomatic bacteriuria is particularly prevalent among RACF residents with chronic indwelling urethral catheters, and antibiotic therapy will not prevent recurrent bacteriuria or symptomatic infections. ${ }^{102}$ Nearly all chronically catheterized patients are bacteriuric; ${ }^{103}$ therefore, the indwelling catheter should be changed prior to the initiation of antibiotic and a urine specimen should be collected from the newly placed catheter. Discontinuation of catheter use and proper aseptic techniques in catheter changing are the keys to preventing UTIs or other urinary complications.

4. Widespread prescribing for upper RTIs or acute bronchitis. ${ }^{34,77,104}$ Among the institutionalized elderly, upper RTIs are usually caused by viral pathogens, where empiric antibiotic treatment is seldom necessary, unless these patients have prolonged symptoms, or preexisting underlying lung diseases. ${ }^{78}$ An effort to differentiate between viral or bacterial origins of presumed RTIs is critical to reduce the inappropriate use of antibiotics. Fundamentally, a minimum set of criteria regarding patient assessment and investigation should be followed prior to making decisions about empirical antibiotic therapy. ${ }^{78}$

5. Prolonged duration of antibiotic treatment. ${ }^{72,81,84}$ There is evidence that antibiotic courses of 7 days or less are as effective as longer treatment durations for the majority of common bacterial infections. ${ }^{105,106}$ On the contrary, unnecessarily prolonged antibiotic treatment will increase a patient's risks of side effects and antibiotic resistance.

6. Widespread prescribing of quinolones as empiric treatment for UTIs. ${ }^{10,75,87}$ Excessive use of these agents is mainly due to their excellent bioavailability, long halflife, and broad-spectrum properties that are ideally suited for the treatment of lower RTI, as well as complicated UTI. ${ }^{107,108}$ Consequently, a high rate of quinolone-resistant gram-negative organisms has been frequently observed in the RACF setting with a high use of quinolones. ${ }^{109-111}$

7. Broad-spectrum or parenteral antibiotic treatment for elderly individuals with advanced dementia or end-stage illness. ${ }^{89,112}$ Several studies have shown that antibiotics may be considered futile (ie, they do not prolong survival or reduce discomfort) at the end stages of life, ${ }^{113,114}$ whereas other studies show contradictory results. ${ }^{15,116}$ In view of the inconclusive evidence, aggressive antibiotic treatment for pneumonia among RACF residents with advanced dementia warrants further investigation and guidance.

\section{Evolving role of the antimicrobial stewardship (AMS) program in RACFs}

AMS programs are integrated activities that help to optimize antimicrobial therapy, ensuring the best clinical outcomes while minimizing the risk of the emergence of antibiotic resistance. ${ }^{117}$ As antibiotic resistance increases and new antibiotic development declines, using existing antibiotics more wisely through AMS programs is an immediate and critical measure that can be used to address this public health crisis. AMS has been increasingly established in the acute care hospital setting, but it remains a relatively new concept in the RACF setting. ${ }^{118}$

In addition to its positive impact on curbing the emergence of antimicrobial resistance, there are other incentives to initiate AMS programs in the RACF setting. The elderly populations in RACFs are generally more susceptible to adverse drug reactions and drug-drug interactions due to their decreased physiological function, comorbidity, and polypharmacy. ${ }^{4}$ Repeated antimicrobial courses, especially the use of broad-spectrum antibiotics, will increase the risk of Clostridium difficile infection. In addition, the elderly populations in RACFs have been shown to be at higher risk for acquiring toxigenic $C$. difficile. ${ }^{119}$ Clearly, an effort to reduce inappropriate or unnecessary use of antibiotics via effective AMS interventions is warranted in this high-risk population to prevent adverse consequences associated with inappropriate antibiotic use, as well as to reduce health care costs.

An international guideline on AMS was jointly published by the Infectious Diseases Society of America and the Society for Healthcare Epidemiology of America in $2007 ;^{120}$ however, this guideline was based primarily on the acute care hospital setting. International guidelines for infection control and prevention in the long-term care setting have recommended the initiation of AMS programs in this setting, ${ }^{1,2}$ although recommendations about feasible AMS interventions specific to this low-resource setting have not been clearly outlined. These guidelines only recommend a minimum standard of monitoring for antimicrobial use and local antimicrobial susceptibilities, while providing routine feedback to relevant authorities. ${ }^{1,2}$ Therefore, specific guidelines on AMS programs targeting the RACF setting remain to be developed. 


\section{Challenges and barriers for implementation of AMS in RACFs}

Several important factors that potentially contribute to widespread and inappropriate antibiotic use among this population have been previously highlighted (see Areas of potential antibiotic misuse). The clinical diagnosis of infectious syndromes among elderly RACF residents is challenging due, in part, to the residents' atypical clinical presentation. The most common symptoms of infection among elderly residents are nonspecific manifestations such as delirium, falls, functional decline, and breakdown of social supports. ${ }^{121}$ Fever was absent or blunted in $20 \%-30 \%$ of well-documented severe infections in the elderly population. ${ }^{4}$ Atypical presentations can potentially lead to delayed diagnosis, late initiation of empiric antimicrobial therapy, and poorer clinical outcomes. ${ }^{5}$ On the other hand, early therapy initiation is often preferred "in case" residents deteriorate, ${ }^{122}$ which has led to antibiotic initiation without confirmed infection. Difficulties in initiating investigations among RACF residents, especially those with cognitive impairment, further complicate the clinical decision-making process. ${ }^{78}$ Midstream urine cultures are almost impossible to obtain from this patient population, especially in the presence of urinary incontinence; this further leads to a lack of microbiological data through which to guide antibiotic treatment.

In the RACF setting, all aspects of resident care, including infection management, are largely driven by nursing staff. ${ }^{123}$ The elderly residents in RACFs have less physician contact compared to hospitalized patients, rendering infection management difficult and mostly driven by nurses or telephone assessment by off-site physicians. ${ }^{124} \mathrm{~A}$ study by Warren et $\mathrm{al}^{77}$ reported that $31 \%$ of residents with severe infections were not noted to have been examined by a physician. Additionally, in a study exploring the process involved in the management of UTIs in RACFs, general practitioners claimed that they seldom visit their patients for a UTI, and they indicated that they relied mostly on the nursing staff's assessments. ${ }^{123}$ Nonetheless, the ability and knowledge of nursing staff to drive infection management remain largely unexplored. Importantly, staffing issues such as rapid staff turnover and low nurse-resident ratios have been previously identified as one of the contributors for higher infection burden among RACF residents. ${ }^{25}$ Furthermore, limited access to infectious diseases specialists, on-site pharmacists, and infection control nurse consultants render the overseeing of antibiotic prescribing difficult, posing additional barriers to the implementation of AMS programs in the RACF setting.
The lack of on-site pathology and radiology support further complicates antibiotic prescribing decisions. ${ }^{126}$ For example, it is generally recommended in the hospital that chest radiograph, pulse oximetry, complete blood count with differential, and blood urea nitrogen be obtained in residents with suspected chest infection, especially in cases of pneumonia. Nonetheless, antibiotic treatment for chest infections in RACFs is almost exclusively empirical because diagnostic investigations to define the etiology are infrequently performed. ${ }^{73,79} \mathrm{~A}$ comprehensive review by Nicolle et $\mathrm{al}^{78}$ has suggested several potential challenges, including the lack of institutional antibiotic policy or published guidelines specific to the RACFs, and limited access to infectious disease experts. All of these factors might hinder appropriate monitoring and stewardship of antibiotic use in this setting.

A cross-national survey in 2006 found significant gaps in infection prevention preparedness in RACFs in many European countries, including the lack of governance structures, inadequate national RACF-specific guidelines or policies, lack of awareness, and major gaps in infection prevention and control expertise. ${ }^{13}$ Similar efforts to identify modifiable factors that influence antibiotic prescribing behavior in the RACF setting is essential to guide further improvement of antibiotic use. Understanding the barriers and facilitators within existing organizational systems is a fundamental step that is needed prior to the introduction of AMS interventions in individual RACFs.

\section{AMS activities in the RACF setting}

The availability and structure of AMS activities in RACFs across different countries are variable. A national survey reported limited AMS activities in the Irish RACF setting. ${ }^{127}$ In contrast, a survey in Nebraska revealed that more than half of participating RACFs reported to have established AMS programs, some with high-intensity interventions such as preauthorization and audit/feedback of antibiotic use. ${ }^{128}$ This survey, which had large participation from RACFs in the rural setting, showed that AMS programs are not limited to hospital-affiliated RACFs or urban areas, but they have become increasingly prevalent across the state. Several studies have reported the outcomes of various strategies for antibiotic use optimization (ie, AMS) in the RACF setting (Table 2).

The studies to date are largely from the US and Canada, with a paucity of data about AMS initiatives in RACF settings in other countries. Extrapolation of data between different countries may not be feasible in view of the variation 


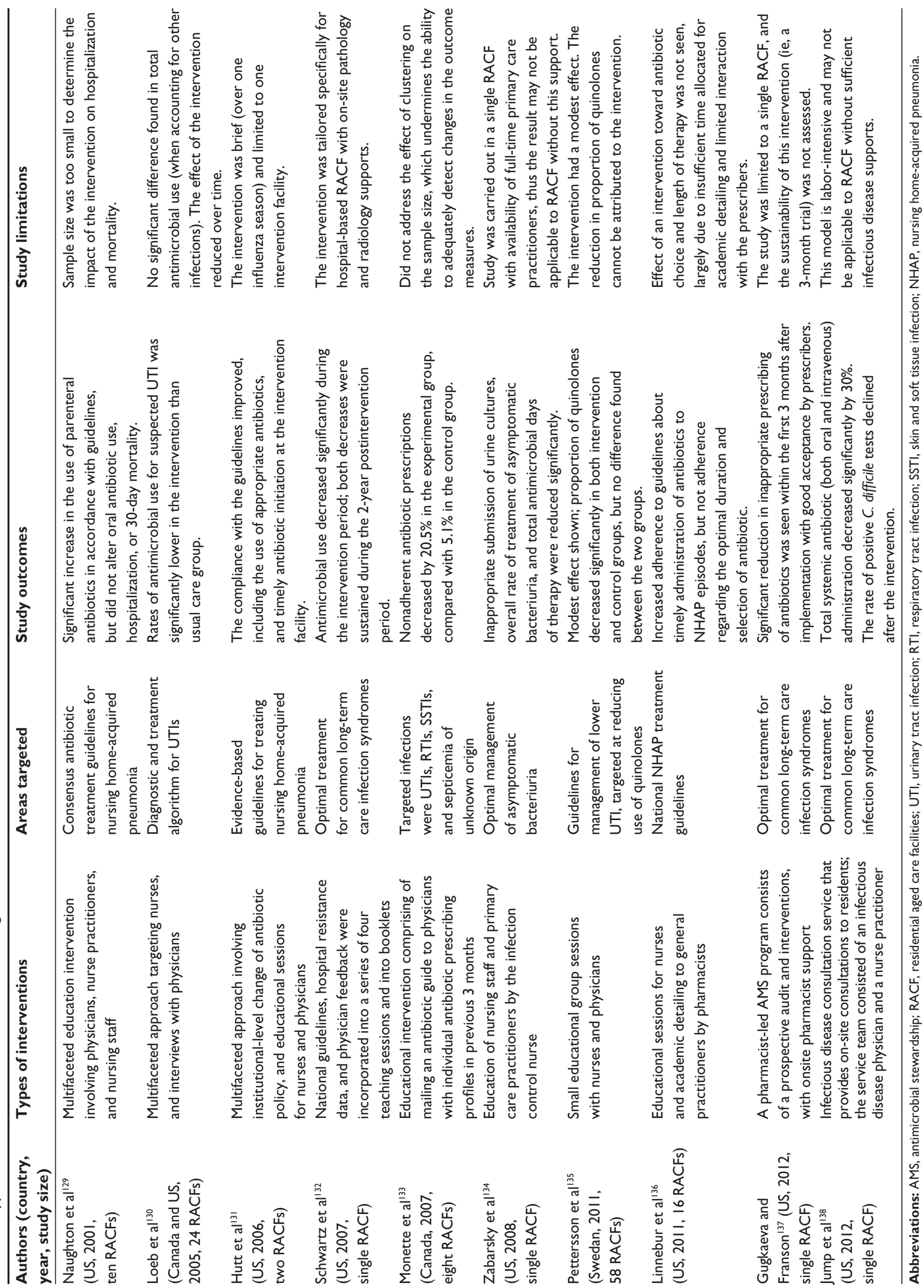


in antibiotic prescribing patterns between countries. For instance, while two US studies used strategies to reduce the high use of fluoroquinolones or IV antibiotics, ${ }^{131,138}$ this may not necessarily be an issue in RACF settings that demonstrate minimal use of fluoroquinolones or IV antibiotics.

International guidelines on AMS have identified two core proactive strategies for promoting AMS in hospital settings. ${ }^{120}$ The first core strategy refer to formulary restriction and/or a requirement for preapproval for administration of specific drugs (front-end approach), and the second is prospective audit that offers an intervention and feedback to prescribers (this is either a front-end or a back-end approach). Other supplemental strategies include educating prescribers, implementing evidence-based guidelines, engaging in an IV-to-oral route switch, de-escalation, dose optimization, or antibiotic cycling, and using computer decision support systems.

There are major differences in AMS interventions between RACF and acute care settings. The types of AMS interventions in the RACF setting have mainly focused on supplementary strategies such as educational interventions or the introduction of antibiotic treatment algorithms and guidelines (Table 2). More proactive hospital-based AMS interventions are limited. Two recent studies have described pharmacist-led or infectious diseases expertise consultation in their AMS models; however, both studies were carried out at hospital-affiliated and Veterans Affairs long-term care facilities with the on-site support of relevant health care professionals. ${ }^{137,138}$ In the US, higher expert support was more commonly available in the Veterans Affairs affiliated facilities than in the generic nursing homes. ${ }^{138,139}$ The feasibility of these labor-intensive AMS models in other RACF settings warrants further investigation. Additionally, AMS interventions in hospitals generally focus on reducing high costs or broad-spectrum antibiotics, and they encourage IV-to-oral conversions. ${ }^{140}$ Conversely, in the RACF setting, the focus lies on promoting appropriate antibiotic use for specific types of common infections (for example, pneumonia and UTIs) or adherence to evidence-based guidelines.

Overall, the studies outlined in Table 2 have shown at least one positive effect on antibiotic prescribing, reflecting the value of AMS initiatives in the RACF setting in improving antibiotic prescribing practices. However, a systematic review has highlighted several methodological limitations of four studies, ${ }^{129,130,133,135}$ which are outlined in Table 2, and no definitive conclusion can be reached about the positive effect of particular AMS interventions. ${ }^{141}$ Additionally, there are major practical challenges to developing a sustainable and effective model of AMS in the RACF setting. Loeb et al ${ }^{130}$ highlighted a decreased effect of interventions in the months following intervention implementation, reflecting the limited sustainability of an AMS program in the participating facilities. ${ }^{130} \mathrm{~A}$ stepwise approach to AMS implementation in RACF settings was proposed by Smith et al, ${ }^{118}$ who suggested that AMS initiatives should commence with the least costly and intrusive approach, with more advanced measures added incrementally based on available resources and institutional needs. Therefore, identifying the limitations of organizational cultures and resources in individual RACF settings is important to inform the development of an AMS program.

\section{Conclusion}

Although antibiotic misuse is problematic in all health care settings, the RACF setting has a particular set of issues that makes any AMS program challenging. RACFs cater to a vulnerable elderly population who have been shown to be at greater risk for acquiring MDR organisms. Increasing evidence proposes that RACF residents serve as an important reservoir for MDR organism transmission, including the emergence of MDR gram-negative organisms. Importantly, prior exposure to antibiotics has been identified as one of the most prominent, yet amendable, risk factors for MDR organism acquisition in an RACF setting. There may have been a misconception that settings with lower resources (such as RACFs) are incapable of supporting AMS programs. Conversely, AMS programs should be viewed as a range of interventions that can be adapted and applied in any health care setting, including in RACF settings.

In an era characterized by a rapid emergence of MDR organisms, an AMS program should be increasingly appreciated across the continuum of care; this might even be more important in a setting that has fewer resources and supports, such as an RACF. While there are barriers to AMS activities in RACFs, activities that are tailored to the context and needs of an RACF setting have been shown to be useful and effective, highlighting the unique role of AMS in this setting. At minimum, an AMS program will require executive support, education capability, and means of monitoring and feeding back antibiotic use to prescribers. Essentially, educational interventions targeting nursing staff and physicians, as well as infection management algorithms and antibiotic treatment guidelines specific to the RACF setting will be critical to promote prudent antibiotic prescribing practices.

\section{Disclosure}

The authors report no conflicts of interest in this work. 


\section{References}

1. Siegel JD, Rhinehart E, Jackson M, Chiarello L. Management of Multidrug-Resistant Organisms in Healthcare Settings, 2006. Atlanta, GA: United States Centers for Disease Control and Prevention; 2006. Available from: http://www.cdc.gov/hicpac/pdf/guidelines/ MDROGuideline2006.pdf. Accessed May 25, 2013.

2. Smith PW, Bennett G, Bradley S, et al; SHEA; APIC. SHEA/APIC guideline: infection prevention and control in the long-term care facility, July 2008. Infect Control Hosp Epidemiol. 2008;29(9): 785-814.

3. Garibaldi RA. Residential care and the elderly: the burden of infection. J Hosp Infect. 1999;43 Suppl:S9-S18.

4. Gavazzi G, Krause KH. Ageing and infection. Lancet Infect Dis. 2002;2(11):659-666.

5. Nicolle LE, Strausbaugh LJ, Garibaldi RA. Infections and antibiotic resistance in nursing homes. Clin Microbiol Rev. 1996;9(1):1-17.

6. Chen H, Chiu AP, Lam PS, et al. Prevalence of infections in residential care homes for the elderly in Hong Kong. Hong Kong Med J. 2008;14(6):444-450.

7. Ingarfield SL, Finn JC, Jacobs IG, et al. Use of emergency departments by older people from residential care: a population based study. Age Ageing. 2009;38(3):314-318.

8. Yates M, Horan MA, Clague JE, Gonsalkorale M, Chadwick PR, Pendleton N. A study of infection in elderly nursing/residential home and community-based residents. J Hosp Infect. 1999;43(2):123-129.

9. Pakyz AL, Dwyer LL. Prevalence of antimicrobial use among United States nursing home residents: results from a national survey. Infect Control Hosp Epidemiol. 2010;31(6):661-662.

10. Pickering TD, Gurwitz JH, Zaleznik D, Noonan JP, Avorn J. The appropriateness of oral fluoroquinolone-prescribing in the long-term care setting. J Am Geriatr Soc. 1994;42(1):28-32.

11. Ben-Ami R, Schwaber MJ, Navon-Venezia S, et al. Influx of extendedspectrum beta-lactamase-producing enterobacteriaceae into the hospital. Clin Infect Dis. 2006;42(7):925-934.

12. Pop-Vicas A, Tacconelli E, Gravenstein S, Lu B, D’Agata EM. Influx of multidrug-resistant, gram-negative bacteria in the hospital setting and the role of elderly patients with bacterial bloodstream infection. Infect Control Hosp Epidemiol. 2009;30(4):325-331.

13. Moro ML, Jans B, Cookson B, Fabry J. The burden of healthcareassociated infections in European long-term care facilities. Infect Control Hosp Epidemiol. 2010;31 Suppl 1:S59-S62.

14. Hughes JM. Study on the efficacy of nosocomial infection control (SENIC Project): results and implications for the future. Chemotherapy. 1988;34(6):553-561.

15. Andersen BM, Rasch M. Hospital-acquired infections in Norwegian long-term-care institutions. A three-year survey of hospital-acquired infections and antibiotic treatment in nursing/residential homes, including 4500 residents in Oslo. J Hosp Infect. 2000;46(4):288-296.

16. Cotter M, Donlon S, Roche F, Byrne H, Fitzpatrick F. Healthcareassociated infection in Irish long-term care facilities: results from the First National Prevalence Study. J Hosp Infect. 2012;80(3):212-216.

17. Eilers R, Veldman-Ariesen MJ, Haenen A, van Benthem BH. Prevalence and determinants associated with healthcare-associated infections in long-term care facilities (HALT) in The Netherlands, May to June 2010. Euro Surveill. 2012;17(34): pii: 20252.

18. Eriksen HM, Iversen BG, Aavitsland P. Prevalence of nosocomial infections and use of antibiotics in long-term care facilities in Norway, 2002 and 2003. J Hosp Infect. 2004;57(4):316-320.

19. Garibaldi RA, Brodine S, Matsumiya S. Infections among patients in nursing homes: policies, prevalence, problems. $N$ Engl J Med. 1981;305(13):731-735.

20. Heudorf U, Boehlcke K, Schade M. Healthcare-associated infections in long-term care facilities (HALT) in Frankfurt am Main, Germany, January to March 2011. Euro Surveill. 2012;17(35). pii: 20256.

21. Marchi M, Grilli E, Mongardi M, Bedosti C, Nobilio L, Moro ML. Prevalence of infections in long-term care facilities: how to read it? Infection. 2012;40(5):493-500.
22. Moro ML, Mongardi M, Marchi M, Taroni F. Prevalence of long-term care acquired infections in nursing and residential homes in the EmiliaRomagna Region. Infection. 2007;35(4):250-255.

23. Moro ML, Ricchizzi E, Morsillo F, et al. Infections and antimicrobial resistance in long term care facilities: a national prevalence study. Ann Ig. 2013;25(2):109-118.

24. Smith M, Atkins S, Worth L, Richards M, Bennett N. Infections and antimicrobial use in Australian residential aged care facilities: a comparison between local and international prevalence and practices. Aust Health Rev. 2013;37(4):529-534.

25. Darnowski SB, Gordon M, Simor AE. Two years of infection surveillance in a geriatric long-term care facility. Am J Infect Control. 1991;19(4):185-190.

26. Engelhart ST, Hanses-Derendorf L, Exner M, Kramer MH. Prospective surveillance for healthcare-associated infections in German nursing home residents. J Hosp Infect. 2005;60(1):46-50.

27. Eriksen HM, Koch AM, Elstrøm P, Nilsen RM, Harthug S, Aavitsland P. Healthcare-associated infection among residents of long-term care facilities: a cohort and nested case-control study. J Hosp Infect. 2007;65(4):334-340.

28. Jackson MM, Fierer J, Barrett-Connor E, et al. Intensive surveillance for infections in a three-year study of nursing home patients. Am J Epidemiol. 1992;135(6):685-696.

29. Roberts C, Roberts J, Roberts RJ. Survey of healthcare-associated infection rates in a nursing home resident population. J Infect Prev. 2010;11(3):82-86.

30. Schulz M, Mielke M, Wischnewski N. Clusters of infectious diseases in German nursing homes: observations from a prospective infection surveillance study, October 2008 to August 2009. Euro Surveill. 2011;16(22). pii: 19881.

31. Stevenson KB, Moore J, Colwell H, Sleeper B. Standardized infection surveillance in long-term care: interfacility comparisons from a regional cohort of facilities. Infect Control Hosp Epidemiol. 2005;26(3): 231-238.

32. Stevenson KB. Regional data set of infection rates for long-term care facilities: description of a valuable benchmarking tool. Am J Infect Control. 1999;27(1):20-26.

33. Wójkowska-Mach J, Gryglewska B, Czekaj J, Adamski P, Grodzicki T, Heczko PB. Infection control: point prevalence study versus incidence study in Polish long-term care facilities in 2009-2010 in the Małopolska Region. Infection. 2013;41(1):1-8.

34. Lim CJ, McLellan SC, Cheng AC, et al. Surveillance of infection burden in residential aged care facilities. Med J Aust. 2012;196(5): 327-331.

35. O'Fallon E, Harper J, Shaw S, Lynfield R. Antibiotic and infection tracking in Minnesota long-term care facilities. J Am Geriatr Soc. 2007;55(8):1243-1247.

36. McGeer A, Campbell B, Emor TG, et al. Definitions of infection for surveillance in long-term care facilities. Am J Infect Control. 1991; 19(1): $1-7$

37. Juthani-Mehta M, Tinetti M, Perrelli E, Towle V, Van Ness PH, Quagliarello V. Diagnostic accuracy of criteria for urinary tract infection in a cohort of nursing home residents. J Am Geriatr Soc. 2007;55(7): 1072-1077.

38. Rothan-Tondeur M, Piette F, Lejeune B, de Wazieres B, Gavazzi G. Infections in nursing homes: is it time to revise the McGeer criteria? J Am Geriatr Soc. 2010;58(1):199-201.

39. Moro ML. A significant step forward: new definitions for surveillance of infections in long-term care. Infect Control Hosp Epidemiol. 2012;33(10):978-980.

40. Stone ND, Ashraf MS, Calder J, et al; Society for Healthcare Epidemiology Long-Term Care Special Interest Group. Surveillance definitions of infections in long-term care facilities: revisiting the McGeer criteria. Infect Control Hosp Epidemiol. 2012;33(10):965-977.

41. Finn JC, Flicker L, Mackenzie E, et al. Interface between residential aged care facilities and a teaching hospital emergency department in Western Australia. Med J Aust. 2006;184(9):432-435. 
42. Warshaw G, Mehdizadeh S, Applebaum RA. Infections in nursing homes: assessing quality of care. J Gerontol A Biol Sci Med Sci. 2001;56(2):M120-M123.

43. Barker WH, Zimmer JG, Hall WJ, Ruff BC, Freundlich CB, Eggert GM. Rates, patterns, causes, and costs of hospitalization of nursing home residents: a population-based study. Am J Public Health. 1994;84(10): 1615-1620.

44. Boockvar KS, Gruber-Baldini AL, Burton L, Zimmerman S, May C, Magaziner J. Outcomes of infection in nursing home residents with and without early hospital transfer. J Am Geriatr Soc. 2005;53(4): 590-596.

45. Dosa D. Should I hospitalize my resident with nursing home-acquired pneumonia? J Am Med Dir Assoc. 2005;6(5):327-333.

46. O'Fallon E, Pop-Vicas A, D'Agata E. The emerging threat of multidrug-resistant gram-negative organisms in long-term care facilities. J Gerontol A Biol Sci Med Sci. 2009;64(1):138-141.

47. Pop-Vicas AE, Mitchell SL, Kandel R, Schreiber R, D’Agata EM. Multidrug-resistant gram-negative bacteria in a long-term care facility: prevalence and risk factors. J Am Geriatr Soc. 2008;56(7): 1276-1280.

48. Muto CA, Jernigan JA, Ostrowsky BE, et al; SHEA. SHEA guideline for preventing nosocomial transmission of multidrug-resistant strains of Staphylococcus aureus and enterococcus. Infect Control Hosp Epidemiol. 2003;24(5):362-386.

49. van Buul LW, van der Steen JT, Veenhuizen RB, et al. Antibiotic use and resistance in long term care facilities. J Am Med Dir Assoc. 2012;13(6):568.e1-13

50. Pacio GA, Visintainer P, Maguire G, Wormser GP, Raffalli J, Montecalvo MA. Natural history of colonization with vancomycinresistant enterococci, methicillin-resistant Staphylococcus aureus, and resistant gram-negative bacilli among long-term-care facility residents. Infect Control Hosp Epidemiol. 2003;24(4):246-250.

51. Smith PW, Seip CW, Schaefer SC, Bell-Dixon C. Microbiologic survey of long-term care facilities. Am J Infect Control. 2000;28(1):8-13.

52. Terpenning MS, Bradley SF, Wan JY, Chenoweth CE, Jorgensen KA, Kauffman CA. Colonization and infection with antibiotic-resistant bacteria in a long-term care facility. J Am Geriatr Soc. 1994;42(10): 1062-1069.

53. March A, Aschbacher R, Dhanji H, et al. Colonization of residents and staff of a long-term-care facility and adjacent acute-care hospital geriatric unit by multiresistant bacteria. Clin Microbiol Infect. 2010;16(7): 934-944.

54. O'Fallon E, Schreiber R, Kandel R, D’Agata EM. Multidrug-resistant gram-negative bacteria at a long-term care facility: assessment of residents, healthcare workers, and inanimate surfaces. Infect Control Hosp Epidemiol. 2009;30(12):1172-1179.

55. Boucher HW, Talbot GH, Bradley JS, et al. Bad bugs, no drugs: no ESKAPE! An update from the Infectious Diseases Society of America. Clin Infect Dis. 2009;48(1):1-12.

56. Benenson S, Cohen MJ, Block C, Stern S, Weiss Y, Moses AE; JIRMI Group. Vancomycin-resistant enterococci in long-term care facilities. Infect Control Hosp Epidemiol. 2009;30(8):786-789.

57. Brugnaro P, Fedeli U, Pellizzer G, et al. Clustering and risk factors of methicillin-resistant Staphylococcus aureus carriage in two Italian long-term care facilities. Infection. 2009;37(3):216-221.

58. Elizaga ML, Weinstein RA, Hayden MK. Patients in long-term care facilities: a reservoir for vancomycin-resistant enterococci. Clin Infect Dis. 2002;34(4):441-446.

59. Garazi M, Edwards B, Caccavale D, Auerbach C, Wolf-Klein G. Nursing homes as reservoirs of MRSA: myth or reality? J Am Med Dir Assoc. 2009; 10(6):414-418.

60. Loeb MB, Craven S, McGeer AJ, et al. Risk factors for resistance to antimicrobial agents among nursing home residents. Am J Epidemiol. 2003;157(1):40-47.

61. Cohen AE, Lautenbach E, Morales KH, Linkin DR. Fluoroquinoloneresistant Escherichia coli in the long-term care setting. Am J Med. 2006;119(11):958-963.
62. Denis O, Jans B, Deplano A, et al. Epidemiology of methicillin-resistant Staphylococcus aureus (MRSA) among residents of nursing homes in Belgium. J Antimicrob Chemother. 2009;64(6):1299-1306.

63. Eveillard M, Charru P, Rufat P, et al. Methicillin-resistant Staphylococcus aureus carriage in a long-term care facility: hypothesis about selection and transmission. Age Ageing. 2008;37(3):294-299.

64. Mendelson G, Hait V, Ben-Israel J, Gronich D, Granot E, Raz $\mathrm{R}$. Prevalence and risk factors of extended-spectrum betalactamase-producing Escherichia coli and Klebsiella pneumoniae in an Israeli long-term care facility. Eur J Clin Microbiol Infect Dis. 2005;24(1):17-22.

65. Rooney PJ, O’Leary MC, Loughrey AC, et al. Nursing homes as a reservoir of extended-spectrum beta-lactamase (ESBL)-producing ciprofloxacin-resistant Escherichia coli. J Antimicrob Chemother. 2009;64(3):635-641.

66. Tinelli M, Cataldo MA, Mantengoli E, et al. Epidemiology and genetic characteristics of extended-spectrum $\beta$-lactamase-producing Gramnegative bacteria causing urinary tract infections in long-term care facilities. J Antimicrob Chemother. 2012;67(12):2982-2987.

67. Kanellakopoulou K, Grammelis V, Baziaka F, et al. Bacterial flora in residents of long-term care facilities: a point prevalence study. J Hosp Infect. 2009;71(4):385-387.

68. Maslow JN, Lee B, Lautenbach E. Fluoroquinolone-resistant Escherichia coli carriage in long-term care facility. Emerg Infect Dis. 2005;11(6):889-894.

69. Sandoval C, Walter SD, McGeer A, et al. Nursing home residents and Enterobacteriaceae resistant to third-generation cephalosporins. Emerg Infect Dis. 2004;10(6):1050-1055.

70. Trick WE, Weinstein RA, DeMarais PL, et al. Colonization of skilledcare facility residents with antimicrobial-resistant pathogens. $\mathrm{J} \mathrm{Am}$ Geriatr Soc. 2001;49(3):270-276.

71. Toubes E, Singh K, Yin D, et al. Risk factors for antibiotic-resistant infection and treatment outcomes among hospitalized patients transferred from long-term care facilities: does antimicrobial choice make a difference? Clin Infect Dis. 2003;36(6):724-730.

72. Daneman N, Gruneir A, Bronskill SE, et al. Prolonged antibiotic treatment in long-term care: role of the prescriber. JAMA Intern Med. 2013;173(8):673-682.

73. Katz PR, Beam TR, Brand F, Boyce K. Antibiotic use in the nursing home. Physician practice patterns. Arch Intern Med. 1990;150(7): 1465-1468.

74. Loeb M, Simor AE, Landry L, et al. Antibiotic use in Ontario facilities that provide chronic care. J Gen Intern Med. 2001;16(6):376-383.

75. Mylotte JM. Measuring antibiotic use in a long-term care facility. $\mathrm{Am}$ J Infect Control. 1996;24(3):174-179.

76. Mylotte JM. Antimicrobial prescribing in long-term care facilities: prospective evaluation of potential antimicrobial use and cost indicators Am J Infect Control. 1999;27(1):10-19.

77. Warren JW, Palumbo FB, Fitterman L, Speedie SM. Incidence and characteristics of antibiotic use in aged nursing home patients. J Am Geriatr Soc. 1991;39(10):963-972.

78. Nicolle LE, Bentley DW, Garibaldi R, Neuhaus EG, Smith PW. Antimicrobial use in long-term-care facilities. SHEA Long-Term-Care Committee. Infect Control Hosp Epidemiol. 2000;21(8):537-545.

79. Zimmer JG, Bentley DW, Valenti WM, Watson NM. Systemic antibiotic use in nursing homes. A quality assessment. J Am Geriatr Soc. 1986;34(10):703-710.

80. Latour K, Catry B, Broex E, et al; European Surveillance of Antimicrobial Consumption Project Group. Indications for antimicrobial prescribing in European nursing homes: results from a point prevalence survey. Pharmacoepidemiol Drug Saf. 2012;21(9):937-944.

81. Daneman N, Gruneir A, Newman A, et al. Antibiotic use in long-term care facilities. J Antimicrob Chemother. 2011;66(12):2856-2863.

82. Rummukainen ML, Kärki T, Kanerva M, Haapasaari M, Ollgren J, Lyytikäinen O. Antimicrobial prescribing in nursing homes in Finland: results of three point prevalence surveys. Infection. 2013;41(2): $355-360$. 
83. McClean P, Hughes C, Tunney M, Goossens H, Jans B; European Surveillance of Antimicrobial Consumption (ESAC) Nursing Home Project Group. Antimicrobial prescribing in European nursing homes. J Antimicrob Chemother. 2011;66(7):1609-1616.

84. McClean P, Tunney M, Gilpin D, Parsons C, Hughes C. Antimicrobial prescribing in residential homes. JAntimicrob Chemother. 2012;67(7): 1781-1790.

85. Stuart RL, Wilson J, Bellaard-Smith E, et al. Antibiotic use and misuse in residential aged care facilities. Intern Med J. 2012;42(10): 1145-1149.

86. Blix HS, Røed J, Sti MO. Large variation in antibacterial use among Norwegian nursing homes. Scand J Infect Dis. 2007;39(6-7): 536-541.

87. Pettersson E, Vernby A, Mölstad S, Lundborg CS. Infections and antibiotic prescribing in Swedish nursing homes: a cross-sectional study. Scand J Infect Dis. 2008;40(5):393-398.

88. Broex E, Catry B, Latour K, et al. Parenteral versus oral administration of systemic antimicrobials in European nursing homes: a pointprevalence survey. Drugs Aging. 2011;28(10):809-818.

89. Chen JH, Lamberg JL, Chen YC, et al. Occurrence and treatment of suspected pneumonia in long-term care residents dying with advanced dementia. J Am Geriatr Soc. 2006;54(2):290-295.

90. Bentley DW, Bradley S, High K, Schoenbaum S, Taler G, Yoshikawa TT; American Geriatrics Society; Gerontological Society of America, Clinical Medicine Section; Infectious Diseases Society of America; Society for Healthcare Epidemiology of America. Practice guideline for evaluation of fever and infection in long-term care facilities. Clin Infect Dis. 2000;31(3):640-653.

91. High KP, Bradley SF, Gravenstein S, et al; Infectious Diseases Society of America. Clinical practice guideline for the evaluation of fever and infection in older adult residents of long-term care facilities: 2008 update by the Infectious Diseases Society of America. J Am Geriatr Soc. 2009;57(3):375-394.

92. Loeb M, Bentley DW, Bradley S, et al. Development of minimum criteria for the initiation of antibiotics in residents of long-term-care facilities: results of a consensus conference. Infect Control Hosp Epidemiol. 2001;22(2):120-124.

93. Olsho LE, Bertrand RM, Edwards AS, et al. Does adherence to the Loeb minimum criteria reduce antibiotic prescribing rates in nursing homes? J Am Med Dir Assoc. 2013;14(4):309. e1-e7.

94. Jones SR, Parker DF, Liebow ES, Kimbrough RC, Frear RS Appropriateness of antibiotic therapy in long-term care facilities. Am J Med. 1987;83(3):499-502.

95. Peron EP, Hirsch AA, Jury LA, Jump RL, Donskey CJ. Another setting for stewardship: high rate of unnecessary antimicrobial use in a veterans affairs long-term care facility. J Am Geriatr Soc. 2013;61(2):289-290.

96. Lee BS, Bhuta T, Simpson JM, Craig JC. Methenamine hippurate for preventing urinary tract infections. Cochrane Database Syst Rev. 2012;10:CD003265.

97. Peralta G, Sánchez MB, Garrido JC, et al. Impact of antibiotic resistance and of adequate empirical antibiotic treatment in the prognosis of patients with Escherichia coli bacteraemia. JAntimicrob Chemother. 2007;60(4):855-863.

98. Abrutyn E, Berlin J, Mossey J, Pitsakis P, Levison M, Kaye D. Does treatment of asymptomatic bacteriuria in older ambulatory women reduce subsequent symptoms of urinary tract infection? J Am Geriatr Soc. 1996;44(3):293-295.

99. Nicolle LE, Mayhew WJ, Bryan L. Prospective randomized comparison of therapy and no therapy for asymptomatic bacteriuria in institutionalized elderly women. Am J Med. 1987;83(1):27-33.

100. Ouslander JG, Schapira M, Schnelle JF, et al. Does eradicating bacteriuria affect the severity of chronic urinary incontinence in nursing home residents? Ann Intern Med. 1995;122(10):749-754.

101. Das R, Towle V, Van Ness PH, Juthani-Mehta M. Adverse outcomes in nursing home residents with increased episodes of observed bacteriuria. Infect Control Hosp Epidemiol. 2011;32(1):84-86.
102. Nicolle LE; SHEA Long-Term-Care-Committee. Urinary tract infections in long-term-care facilities. Infect Control Hosp Epidemiol. 2001;22(3):167-175.

103. Warren JW, Tenney JH, Hoopes JM, Muncie HL, Anthony WC. A prospective microbiologic study of bacteriuria in patients with chronic indwelling urethral catheters. J Infect Dis. 1982;146(6):719-723.

104. Vergidis P, Hamer DH, Meydani SN, Dallal GE, Barlam TF. Patterns of antimicrobial use for respiratory tract infections in older residents of long-term care facilities. J Am Geriatr Soc. 2011;59(6):1093-1098.

105. Rafailidis PI, Pitsounis AI, Falagas ME. Meta-analyses on the optimization of the duration of antimicrobial treatment for various infections. Infect Dis Clin North Am. 2009;23(2):269-276, Table of Contents.

106. Lutters M, Vogt-Ferrier NB. Antibiotic duration for treating uncomplicated, symptomatic lower urinary tract infections in elderly women. Cochrane Database Syst Rev. 2008CD001535.

107. Bonomo RA. Multiple antibiotic-resistant bacteria in long-term-care facilities: An emerging problem in the practice of infectious diseases. Clin Infect Dis. 2000;31(6):1414-1422.

108. Ferrara AM. New fluoroquinolones in lower respiratory tract infections and emerging patterns of pneumococcal resistance. Infection. 2005;33(3):106-114.

109. Flournoy DJ. Antimicrobial susceptibilities of bacteria from nursing home residents in Oklahoma. Gerontology. 1994;40(1):53-56.

110. Viray M, Linkin D, Maslow JN, et al. Longitudinal trends in antimicrobial susceptibilities across long-term-care facilities: emergence of fluoroquinolone resistance. Infect Control Hosp Epidemiol. 2005;26(1):56-62.

111. Vromen M, van der Ven AJ, Knols A, Stobberingh EE. Antimicrobial resistance patterns in urinary isolates from nursing home residents. Fifteen years of data reviewed. J Antimicrob Chemother. 1999;44(1): 113-116.

112. D'Agata E, Mitchell SL. Patterns of antimicrobial use among nursing home residents with advanced dementia. Arch Intern Med. 2008;168(4):357-362.

113. Hurley AC, Volicer B, Mahoney MA, Volicer L. Palliative fever management in Alzheimer patients. quality plus fiscal responsibility. ANS Adv Nurs Sci. 1993;16(1):21-32.

114. van der Steen JT, Ooms ME, van der Wal G, Ribbe MW. Pneumonia: the demented patient's best friend? Discomfort after starting or withholding antibiotic treatment. J Am Geriatr Soc. 2002;50(10): 1681-1688.

115. Givens JL, Jones RN, Shaffer ML, Kiely DK, Mitchell SL. Survival and comfort after treatment of pneumonia in advanced dementia. Arch Intern Med. 2010;170(13):1102-1107.

116. Van Der Steen JT, Pasman HR, Ribbe MW, Van Der Wal G, Onwuteaka-Philipsen BD. Discomfort in dementia patients dying from pneumonia and its relief by antibiotics. Scand $J$ Infect Dis. 2009;41(2):143-151.

117. Gerding DN. The search for good antimicrobial stewardship. Jt Comm J Qual Improv. 2001;27(8):403-404.

118. Smith P, Watkins K, Miller H, VanSchooneveld T. Antibiotic stewardship programs in long-term care facilities. Ann Longterm Care. 2011;19(4):20-25.

119. Boone JH, Goodykoontz M, Rhodes SJ, et al. Clostridium difficile prevalence rates in a large healthcare system stratified according to patient population, age, gender, and specimen consistency. Eur J Clin Microbiol Infect Dis. 2012;31(7):1551-1559.

120. Dellit TH, Owens RC, McGowan JE, et al; Infectious Diseases Society of America; Society for Healthcare Epidemiology of America. Infectious Diseases Society of America and the Society for Healthcare Epidemiology of America guidelines for developing an institutional program to enhance antimicrobial stewardship. Clin Infect Dis. 2007;44(2):159-177.

121. Jarrett PG, Rockwood K, Carver D, Stolee P, Cosway S. Illness presentation in elderly patients. Arch Intern Med. 1995;155(10): 1060-1064. 
122. Brown NK, Thompson DJ. Nontreatment of fever in extended-care facilities. N Engl J Med. 1979;300(22):1246-1250.

123. Schweizer AK, Hughes CM, Macauley DC, O’Neill C. Managing urinary tract infections in nursing homes: a qualitative assessment. Pharm World Sci. 2005;27(3):159-165.

124. Beier MT. Management of urinary tract infections in the nursing home elderly: a proposed algorithmic approach. Int J Antimicrob Agents. 1999;11(3-4):275-284.

125. Zimmerman S, Gruber-Baldini AL, Hebel JR, Sloane PD, Magaziner J. Nursing home facility risk factors for infection and hospitalization: importance of registered nurse turnover, administration, and social factors. J Am Geriatr Soc. 2002;50(12):1987-1995.

126. Simor AE. The role of the laboratory in infection prevention and control programs in long-term-care facilities for the elderly. Infect Control Hosp Epidemiol. 2001;22(7):459-463.

127. Donlon S, Roche F, Byrne H, Dowling S, Cotter M, Fitzpatrick F. A national survey of infection control and antimicrobial stewardship structures in Irish long-term care facilities. Am J Infect Control. 2013;41(6):554-557.

128. Van Schooneveld T, Miller H, Sayles H, Watkins K, Smith PW. Survey of antimicrobial stewardship practices in Nebraska long-term care facilities. Infect Control Hosp Epidemiol. 2011;32(7):732-734.

129. Naughton BJ, Mylotte JM, Ramadan F, Karuza J, Priore RL. Antibiotic use, hospital admissions, and mortality before and after implementing guidelines for nursing home-acquired pneumonia. J Am Geriatr Soc. 2001;49(8):1020-1024.

130. Loeb M, Brazil K, Lohfeld L, et al. Effect of a multifaceted intervention on number of antimicrobial prescriptions for suspected urinary tract infections in residents of nursing homes: cluster randomised controlled trial. BMJ. 2005;331(7518):669.

131. Hutt E, Ruscin JM, Corbett K, et al. A multifaceted intervention to implement guidelines improved treatment of nursing home-acquired pneumonia in a state veterans home. J Am Geriatr Soc. 2006;54(11): 1694-1700
132. Schwartz DN, Abiad H, DeMarais PL, et al. An educational intervention to improve antimicrobial use in a hospital-based long-term care facility. J Am Geriatr Soc. 2007;55(8):1236-1242.

133. Monette J, Miller MA, Monette M, et al. Effect of an educational intervention on optimizing antibiotic prescribing in long-term care facilities. J Am Geriatr Soc. 2007;55(8):1231-1235.

134. Zabarsky TF, Sethi AK, Donskey CJ. Sustained reduction in inappropriate treatment of asymptomatic bacteriuria in a long-term care facility through an educational intervention. Am J Infect Control. 2008;36(7):476-480.

135. Pettersson E, Vernby A, Mölstad S, Lundborg CS. Can a multifaceted educational intervention targeting both nurses and physicians change the prescribing of antibiotics to nursing home residents? A cluster randomized controlled trial. J Antimicrob Chemother. 2011;66(11): 2659-2666.

136. Linnebur SA, Fish DN, Ruscin JM, et al. Impact of a multidisciplinary intervention on antibiotic use for nursing home-acquired pneumonia. Am J Geriatr Pharmacother. 2011;9(6):442-450. e1.

137. Gugkaeva Z, Franson M. Pharmacist-led model of antibiotic stewardship in a long-term care facility. Ann Longterm Care. 2012;20(10): 22-26.

138. Jump RL, Olds DM, Seifi N, et al. Effective antimicrobial stewardship in a long-term care facility through an infectious disease consultation service: keeping a LID on antibiotic use. Infect Control Hosp Epidemiol. 2012;33(12):1185-1192.

139. Caprio TV, Karuza J, Katz PR. Profile of physicians in the nursing home: time perception and barriers to optimal medical practice. J Am Med Dir Assoc. 2009;10(2):93-97.

140. Owens RC Jr. Antimicrobial stewardship: concepts and strategies in the 21st century. Diagn Microbiol Infect Dis. 2008;61(1):110-128.

141. Fleming A, Browne J, Byrne S. The effect of interventions to reduce potentially inappropriate antibiotic prescribing in long-term care facilities: a systematic review of randomised controlled trials. Drugs Aging. 2013;30(6):401-408.
Clinical Interventions in Aging

\section{Publish your work in this journal}

Clinical Interventions in Aging is an international, peer-reviewed journal focusing on evidence-based reports on the value or lack thereof of treatments intended to prevent or delay the onset of maladaptive correlates of aging in human beings. This journal is indexed on PubMed Central, MedLine, the American Chemical Society's 'Chemical Abstracts

\section{Dovepress}

Service' (CAS), Scopus and the Elsevier Bibliographic databases. The manuscript management system is completely online and includes a very quick and fair peer-review system, which is all easy to use. Visit http://www.dovepress.com/testimonials.php to read real quotes from published authors. 